\title{
Smart Final Year Project Archive System Using Laravel Framework with Email Notification (SFYPAS)
}

\author{
Abidah Mat Taib ${ }^{1 *}$, Noor Atirah Mohd Shukri², Nurul Hidayah Ahmad Zukri \\ Norlizawati Ghazali ${ }^{4}$, \\ ${ }^{1,2,3}$ Faculty of Computer and Mathematical Sciences, Universiti Teknologi MARA, \\ Perlis Branch, Arau, Perlis, Malaysia \\ ${ }^{4}$ Academy of Language Studies, Universiti Teknologi MARA, \\ Perlis Branch, Arau, Perlis, Malaysia \\ Corresponding author:*abidah@uitm.edu.my \\ Received Date: 31 August 2020 \\ Accepted Date: 7 October 2020
}

\begin{abstract}
Final Year Project (FYP) is a compulsory requirement for graduation of every bachelor programme in Universiti Teknologi MARA (UiTM). Finding a topic for the final year project is quite challenging. However, being able to access previous FYP thesis helps students to generate some ideas. Supervisors and lecturers can also determine whether the proposed project is already among the previous research project or a new one. Unfortunately, the past FYP thesis is usually kept in a specific thesis room. Hence, this will make going to the thesis room and searching the thesis for references quite burdensome. The lack of electronic management for FYP thesis causes several problems in arrangement and search methods. This project aims to develop Smart Final Year Project Archive System (SFYPAS) using Laravel Framework and evaluate the system in terms of Technology Acceptance Model (TAM). SFYPAS is developed using Laravel framework and the methodology used throughout the project is using Software Development Life Cycle (SDLC). The system was tested based on its functionality, user acceptance with TAM and heuristic evaluation by an expert. It was tested on thirty respondents who shared their feedback by answering a set of questionnaires upon completing the testing. The result shows that the mean for user acceptance with TAM in terms of perceived ease of use is 4.27, while perceived usefulness is 4.47. Thus, it shows that the respondents are satisfied with the system in terms of its perceived usefulness. In conclusion, this research has achieved the objectives where it eases the user by providing a web-based smart archive system as a platform to access the past FYP thesis. For future work, the system can be improved by adding a search engine that implements any searching algorithm to yield better results.
\end{abstract}

Keywords: Web-based application, Archive, FYP thesis, Laravel Framework, Technology Acceptance Model (TAM)

\section{INTRODUCTION}

In Universiti Teknologi MARA (UiTM), Final Year Project (FYP) is a compulsory requirement of graduation in bachelor programmes in the Faculty of Computer and Mathematical Science (FSKM). Normally, every third-year student should register for their project under the course code CSP600 and CSP650. It is a two-semester long activity in which every student has to complete their projects under the supervision of one of the lecturers in FSKM.

Each branch of UiTM in Malaysia has its own management system to manage and monitor information regarding the FYP thesis that have been done every semester. Nevertheless, the management of the information process is somehow very rigid when some branches are still using a paper-based system or 
manual system, especially for managing completed FYP projects which will cause many problems in the future such as missing information, and data manipulation. Generally, the process and procedure involving paper-based system is time consuming as the students need to go to the supervisors' office or thesis room to view and get access to the projects. The students found that it is burdensome for them to acquire the sources that they need, and it causes difficulty for the students to generate ideas or topics that they want to propose for their current FYP projects since they need to manually search the previous research or projects from the supervisors' or thesis room.

Besides, supervisors face the difficulty in storing and managing the FYP thesis because each supervisor have many supervisees to be handled. Supervisors also encountered difficulties in retrieving their supervision history. Most supervisors need the information regarding their supervision such as the students' list that they have supervised and the information of the FYP thesis. This information is vital for supervisors to update their current curriculum vitae $(\mathrm{CV})$ and for career advancement purposes. However, technological advancement has offered a better option for information storage and management. Most organisation now are applying a paperless documentation strategy to decrease the need to store the monstrous sum of physical papers and save their overall running expenses (Abidin \& Hussin, 2018).

As the number of the students increases every year, which results in an increase in the number of projects submitted, the coordinators have difficulty monitoring and managing which topics or titles that have already been submitted. There are possibilities that the proposed project titles may overlap with existing project titles. This problem will affect students' marks, should it occur, as overlapping title decreases the novelty of a project.

Thus, an archive system needs to be implemented to solve the management of completed FYP projects problem, especially to forecast future research area in the faculty as it is related to the potential of industry linkages, graduate employability and future training. It is because sometimes the administrator might overlook a particular research area when forecasting for the future area of research in the faculty. Administrators also face difficulty in managing and giving recommendations on which training should be conducted by the university, especially for the FYP students, in assisting them to successfully complete the FYP.

A research conducted by the Faculty of Information Technology and Computing in Rabigh, King Abdulaziz University on 62 students indicates that 91.9\% students read the previous students' FYP thesis and $95.2 \%$ students feel that the development of a website for archiving students' project in the faculty is a good idea (Malik, et al., 2018). Therefore, a better way to manage FYP thesis in UiTM Perlis is by applying a paperless documentation method implemented using a web-based system on Laravel framework. Thus, this paper presents the study on Smart Final Year Project Archive System with Email Notification (SFYPAS) that was developed using Laravel Framework.

SFYPAS can help administrators and supervisors to manage past FYP thesis as well as assist students to generate ideas and make decision by choosing the best topics for their current final year projects based on what research area they are interested in. Hence, the FYP thesis management is more efficient because it classified projects according to the related field research area such as mobile application, internet of things (IoT), gamification and others. Moreover, the system could filter and give recommendations of the research or projects based on the keywords. With all of these features, it is more convenient for the students and lecturers (supervisors, coordinators and examiners) to search and manage the FYP thesis. SFYPAS, being a web-based system is more organized and applicable to be reached through the Internet which can increase productivities for lecturers and students. The rest of the paper is organized as follows. Section 2 discusses the literature review and related work. Then, section 3 presents the overview of the SFYPAS system that includes the system design and the implementation of the system. Subsequently, 
section 4 highlights the result and analysis of the testing conducted in the study. Finally, section 5 offers the conclusion and recommendation.

\section{LITERATURE REVIEW}

An archive stores published and unpublished documents and these documents are unique, specialised or rare within any format (Edzan, 2015). These documents are usually in the PDF and Docs format. It means that an archive is a compilation of records produced or collected by one person or institution, chosen for lifelong protection as proof of completed tasks by that individuals and institutions.

Archiving is crucial for managing information records where the information collected by an institution or individual might need to be meticulously managed and monitored to be appropriately utilised. The compilation of records that is not archived is difficult to locate, not secure and could not be appropriately disseminated if it is stored in a local environment such as employees' laptops. According to Securedatamgt (2015), the top three importance of archiving are to prevent data loss, records for legal requirements and increase security management.

This project's web technology includes markup language and multimedia packages where PHP is used as a programming language that generates dynamic Hypertext Markup Language (HTML), Laravel framework and MVC architecture.

\section{Web Application Framework}

A web application framework is a framework that is designed to support the development of web applications including web services, web resources, and web APIs. Nowadays, the use of software framework is the most popular in web application development due to the advancement of technology in web application programming as well as the standardization it provides in building and deploying web applications on the World Wide Web. There are a variety of frameworks available in the market such as Laravel, Symfony, CakePHP and many more. Each of the framework has its own advantages and specialisation that can be implemented in web application. Table 1 shows the comparison between Laravel, Symfony and CakePHP framework.

\section{Laravel Framework}

It is an open-source PHP web framework developed by Taylor Otwell in 2011 that pursues the ModelView-Controller (MVC) architecture pattern. This framework is powerful and straightforward making it easy to be understood by beginners. Laravel gives authentication, routing, caching and great database migration tools that enable developers to build complex applications (Chen, Fan \& Zhan, 20 17).

\section{Symphony Framework}

It is developed by French Fabien Potencier in 2005. The framework is suitable for complex applications and it requires developer with great aptitudes. It provides flexibility and excellent performance, a few choices for extensibility and reusable components that minimise cost and time (Laaziri, Benmoussa, Khoulji, Larbi, \& Yamami, 2019). 


\section{CakePHP Framework}

It is released in 2005 which is a PHP based framework (Laaziri et al., 2019) and is utilised to build enormous scale applications. It bolsters the use of HTML, JavaScript, AJAX and so forth. CakePHP is most suitable with PHP 4 and PHP 5 and has the management of security, session and request (Hustinawati, Kurnia Himawan, \& Latifah, 2014).

Table 1 Comparison between Laravel, Symfony and CakePHP Framework (Beta Social Compare, 2019)

\begin{tabular}{|l|l|l|l|}
\hline Features & Laravel & CakePHP & Symfony \\
\hline Latest Version & 5.5 & 2.6 .2 & 2.6 .4 \\
\hline $\begin{array}{l}\text { Object-relational } \\
\text { mapping (ORM) }\end{array}$ & $\begin{array}{l}\text { ELOQUENT } \\
\text { ORM }\end{array}$ & Custom & Propel, Doctrine \\
\hline $\begin{array}{l}\text { Template } \\
\text { System }\end{array}$ & $\begin{array}{l}- \text { PHP } \\
- \text { Custom }\end{array}$ & $\begin{array}{l}- \text { Custom but smarty } \\
- \text { Twig }\end{array}$ & $\begin{array}{l}\text { - PHP } \\
- \text { Twig }\end{array}$ \\
\hline Cache Storage & $\begin{array}{l}\text { - File system } \\
- \text { Database } \\
- \text { Xcache } \\
- \text { Memory (Arrays) }\end{array}$ & $\begin{array}{l}\text { - Redis } \\
- \text { APC File }\end{array}$ & $\begin{array}{l}\text { - HTTP } \\
\text { - APC } \\
\text { eAccelerator } \\
- \text { Xcache }\end{array}$ \\
\hline Code Generation & CLI & CLI & CLI \\
\hline XSS & $\checkmark$ & $\checkmark$ & $\checkmark$ \\
\hline $\begin{array}{l}\text { SQL } \\
\text { injection }\end{array}$ & $\checkmark$ & $\checkmark$ & $\checkmark$ \\
\hline $\begin{array}{l}\text { Multiple } \\
\text { database }\end{array}$ & $\checkmark$ & $\checkmark$ & $\checkmark$ \\
\hline
\end{tabular}

Based on the comparison above, it can be concluded that Laravel is the most suitable framework to be implemented on the web application as a web development technique as compared to Symfony and CakePHP. It is because Laravel uses database as cache storage. It is the latest framework compared to the Symfony and CakePHP which was released in 2011 and requires not much skills to implement.

\section{MVC Architecture}

Model-View-Controller architecture is a common design architecture utilised in website design or web application development (Verma, 2014). The MVC pattern can be divided into three major roles such as model, view and controller. Figure 1 shows the MVC architecture.

\section{1) Model}

The model is a piece of the system that controls all the tasks associated with data such as validation, authentication and database. It contains techniques to access data from the databases and makes a reusable class library available in order to minimise the difficulty of the code that the majority of developer faces (Pop \& Altar, 2014). 


\section{2) View}

The view is usually known as templates or web design because it controls how the data is exhibited and provides data gathering methods from users when they interact with it. The technologies majorly used in views are CSS, JavaScript and HTML (Pop \& Altar, 2014).

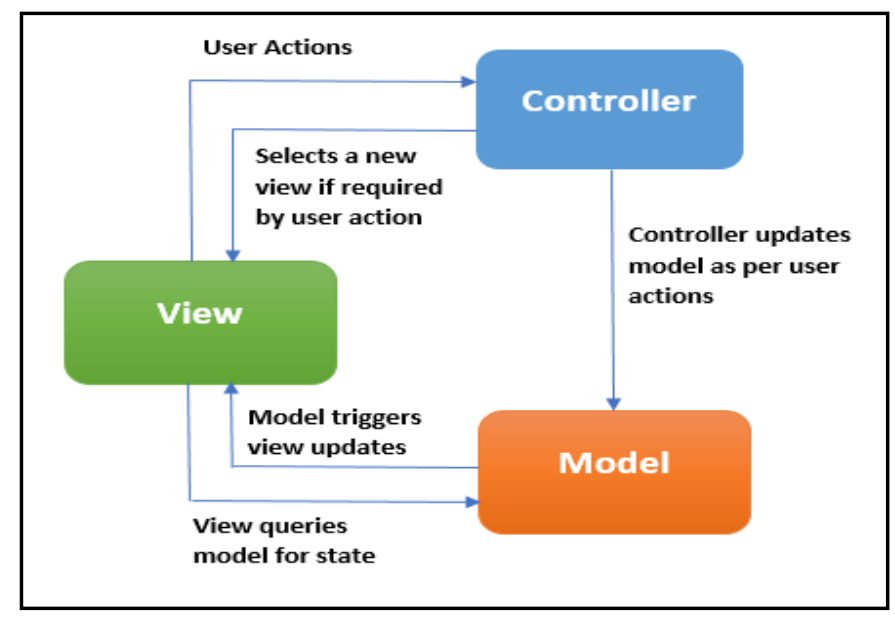

Figure 1: MVC Architecture

\section{3) Controller}

The controller manages event handling where the event can be generated when a user interacts with the application or a system process. The controller will respond to the requests with the data requested. For example, the controller retrieves the required data by interacting with the model and it generates the data to the view (Pop \& Altar, 2014).

\section{RELATED WORK}

There are three existing systems that have applied the archive in managing FYP thesis in universities. The systems are considered based on the type of users and the functions offered. These three systems related to the Smart Final Year Project Archive System (SFYPAS) are explained below. Summary of comparison of Related Work to SFYPAS is listed in Table 2.

\section{Web-based Archive Management and Student Guidance for Final Year Project (GPOrganize)}

GPOrganize provides an archive system of previous FYP thesis that is used by King Abdulaziz University, Rabigh, Saudi Arabia. The system is offered only for the university students to search the related FYP thesis as their reference. There are two types of users namely the students and administrators. After the students have completed their FYP thesis, they need to add their project for archive purposes. Therefore, the upcoming students will be able to view their projects as reference. The students need to login into the system in order to get the ability to access the archived thesis. The system displays lists of all available thesis and the details according to the students' keyword. Moreover, students also can download the report. The additional functions of this system are that it provides the possibility for students to communicate with their supervisors, and student guidance in the form of templates and guidelines, and attachments of lists of essential links to external resources (Malik, et al., 2018). 


\section{eTheses of Universiti Utara Malaysia}

eTheses is a system used to store students' thesis from Universiti Utara Malaysia (UUM). This system is managed by the university's library which is Perpustakaan Sultanah Bahiyah. The eTheses can only be fully accessed by the staff and students from UUM. This means that users from other universities cannot access this system. Besides, this system used open access repository which is Eprint 3 that is flexible with the Open Archives Initiative Protocol for Metadata Harvesting (Etheses, 2019).

\section{Elmtiyaz of Universiti Sains Islam Malaysia}

Elmtiyaz is a system that stores all types of university records such as examination papers, conferences or workshop items and academic project papers. This system allows users from any academic university in Malaysia to access the system. There are two types of users such as students and administrators. The additional function in this system is that it provides notification through email if there are new resources updated onto the system. To get this notification, users need to signup by entering their email address. Besides, this system uses an open-access repository which is Dspace as a digital archives system (Elmtiyaz, 2019).

Table 2: Comparison of Related work with SFYPAS

\begin{tabular}{|c|c|c|}
\hline Title & Tool and Technology Used & Functions \\
\hline GPOrganize & $\begin{array}{l}\text { PHP, } \quad \text { Macromedia } \\
\text { Dreamweaver, XAMPP }\end{array}$ & $\begin{array}{l}\text { Allow students to archive FYP thesis and the possibility to } \\
\text { download the previous FYP thesis. }\end{array}$ \\
\hline eTheses & $\begin{array}{l}\text { Open-source repository: } \\
\text { Eprint3 }\end{array}$ & $\begin{array}{l}\text { Limited access to the archive thesis for users from any } \\
\text { universities except UUM. }\end{array}$ \\
\hline Elmtiyaz & $\begin{array}{l}\text { Open-source repository: } \\
\text { Dspace }\end{array}$ & $\begin{array}{l}\text { Provides access to academic project papers, conference or } \\
\text { workshop. }\end{array}$ \\
\hline $\begin{array}{lr}\text { Smart } & \text { Final } \\
\text { Project } & \text { Year } \\
\text { System } & \text { Using } \\
\text { Laravel } & \text { Framework } \\
\text { (SFYPAS) }\end{array}$ & $\begin{array}{l}\text { Programming Language: } \\
\text { PHP, JavaScript, AJAX } \\
\text { Web Application method: } \\
\text { Laravel Framework } \\
\text { Platforms to develop the } \\
\text { system: Bracket, } \\
\text { Implementation of web } \\
\text { application: XAMPP } \\
\begin{array}{l}\text { Deployment of web } \\
\text { application: Internet } \\
\text { Explorer, Chrome }\end{array}\end{array}$ & $\begin{array}{l}\text { Similar features: } \\
\text { - Provides archive for the previous FYP thesis. } \\
\text { - Provides the possibility to download the previous FYP } \\
\text { thesis. } \\
\text { Different features: } \\
\text { - Supervisors can search for their history of supervision. } \\
\text { - Coordinators can monitor the detail of FYP thesis of } \\
\text { her/his student. } \\
\text { - Examiners can obtain the details about the previous FYP } \\
\text { thesis to avoid duplication. } \\
\text { - Administrators can obtain the information and view the } \\
\text { current and previous percentage of the research area in the } \\
\text { faculty. }\end{array}$ \\
\hline
\end{tabular}


As can be seen in Table 2, the review of related works highlights the importance of FYP management system and put forward the significant contribution of SFYPAS as one of the modules in a complete Final Year Project Integrated Management System (FYPIMS) that can be accessed online to find the information and details regarding FYP thesis. It can be retrieved easily especially by FYP students as their project's references. The development of Smart Final Year Project Archive System (SFYPAS) is necessary to ease students, supervisors, coordinators and examiners in managing and searching for FYP thesis.

\section{SFYPAS: SYSTEM OVERVIEW}

The SFYPAS was developed to store and manage the FYP thesis done by the previous FYP students from FSKM UiTM Perlis by providing an archive system that will help filter the previous FYP thesis. Three different users can access the system namely students, lecturers (supervisor, coordinator and examiner) and administrators who have their own purpose and tasks. Selected lecturer or staff within the faculty will be offered to be the administrator of the system. Through this system, the supervisors, coordinators, and examiners can view their supervision, coordinate and examine history respectively. The students can archive their FYP thesis. After archiving a thesis, the supervisor needs to view the uploaded thesis by their supervisees and choose to approve or reject it. An email notification will be sent to alert his or her supervisees about the response. If the thesis does not meet the standard requirement, the supervisor can reject the uploaded thesis.

This project used a web-based system as a platform and also implemented Laravel Framework. The programming language for Laravel Framework is mostly in PHP including Object Oriented PHP. The methodology that was chosen and applied in this project is Waterfall Model as it covers several phases such as requirements analysis, design, implementation, testing and documentation. The typical design used were Entity Relationship Diagram (ERD) and Data Flow Diagram (DFD). Context diagram is a diagram that consists of a process and illustrates the scope of a system. It is also the highest level of DFD that configures all inputs to the system or output of the system where it gives illustration to the whole system (Aminin, Dacholfany, Mujib, \& Huda, 2018). Figure 1 shows the context diagram that represents the whole process in the archive system. Data Flow Diagram for the web application is shown in Figure 2 .

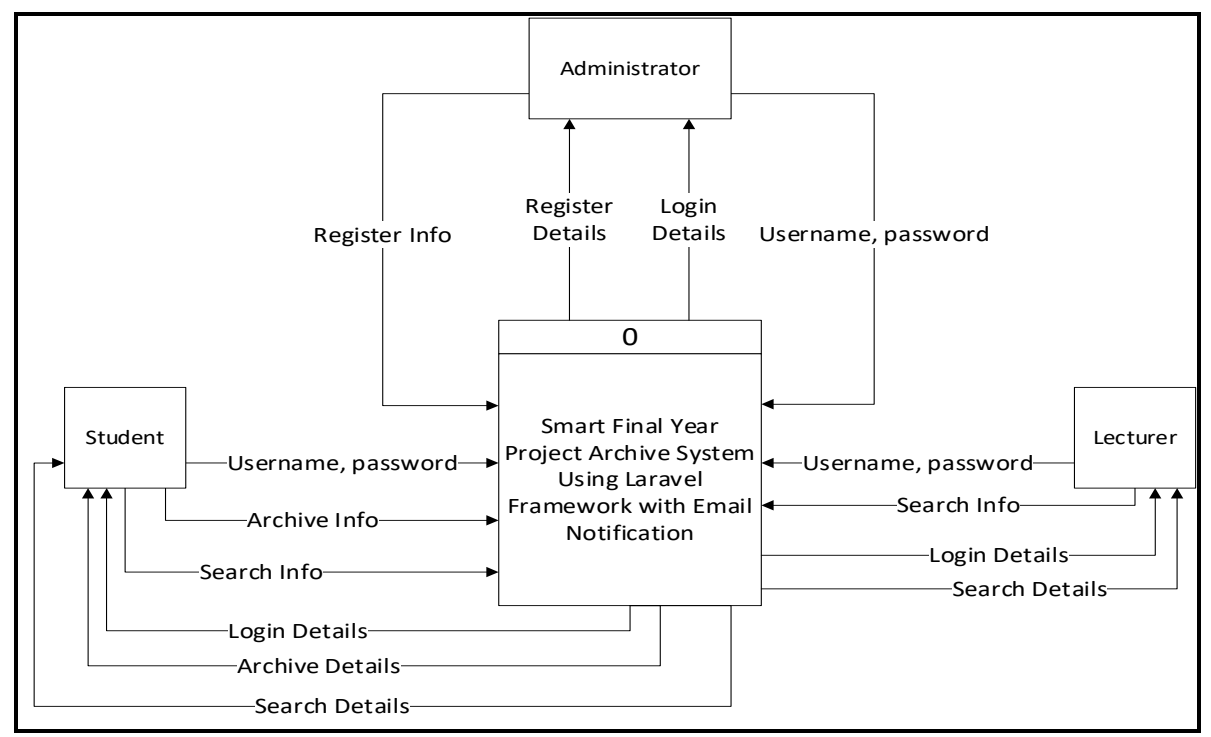

Figure 1: Context Diagram 


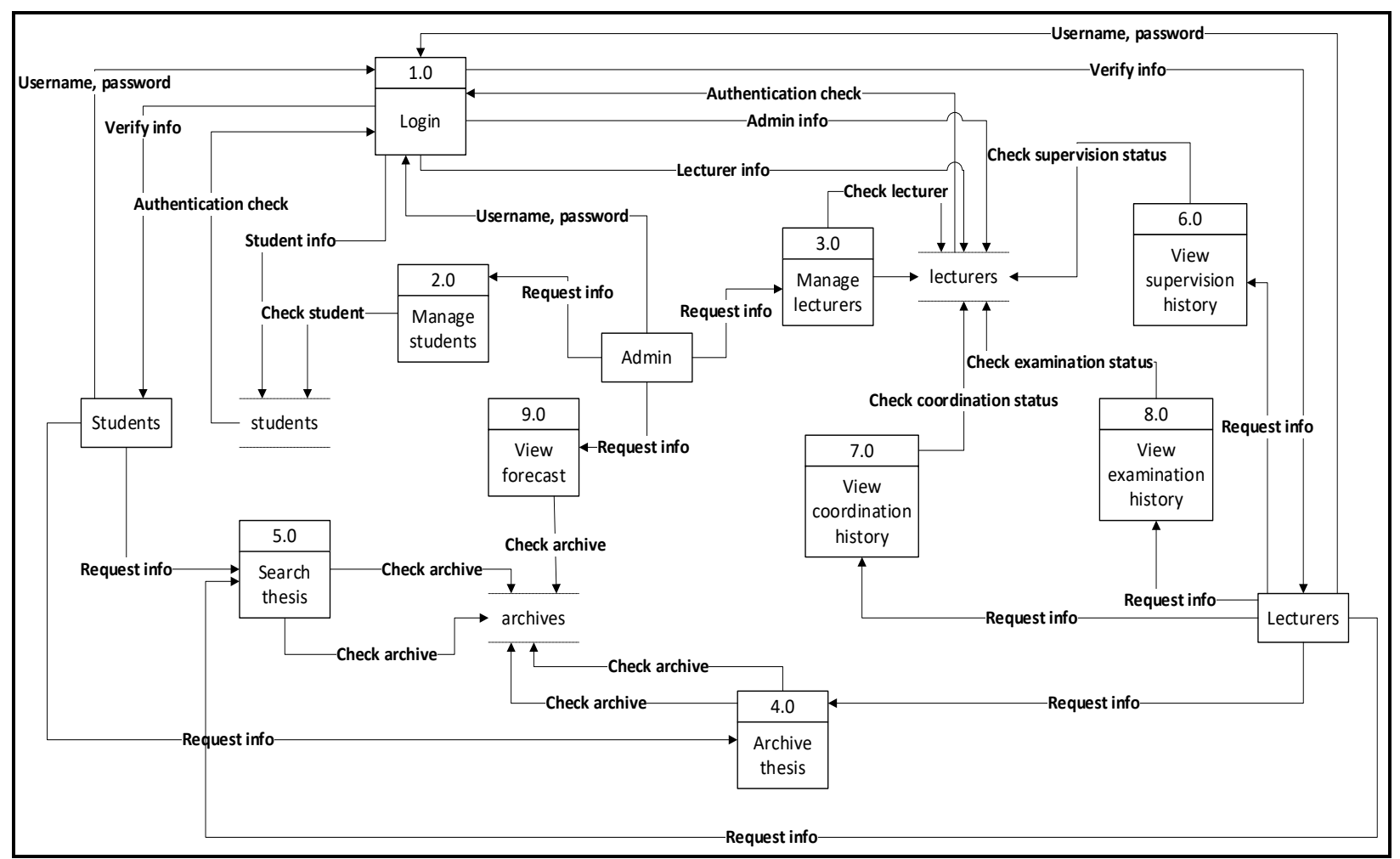

Figure 2: Data Flow Diagram

Figure 3 depicts the homepage interface of SFYPAS. There are three different users who are student, lecturer and administrator. Once the user login into the system, the system will verify the authentication and compare it with the database. If the login process is successful, the user can use the system based on tasks assigned for each role.

Figure 4 displays the interface of the archive thesis. The students use this page to archive their complete thesis into the system for future usage. Students need to archive their completed FYP thesis into this system by entering the details in the form such as title, abstract, supervisor, coordinator, and examiner name. If the form is incomplete, the system will notify the users with an error message popup.

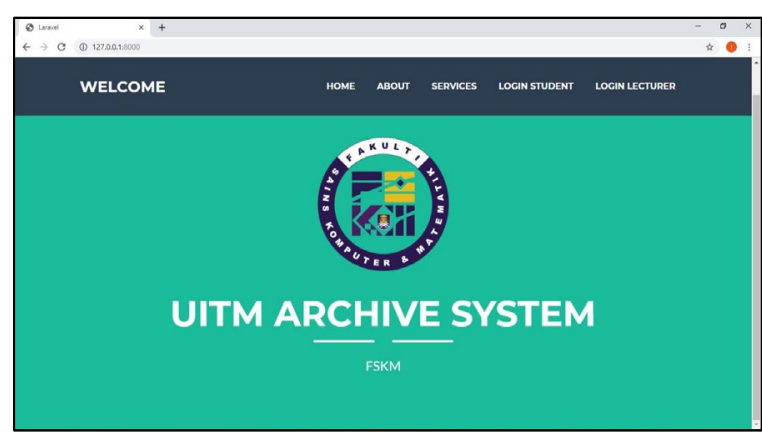

Figure 3: Homepage Interface Design

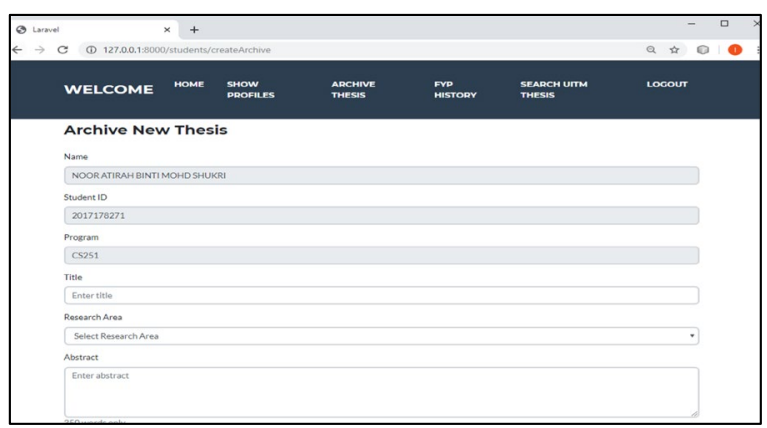

Figure 4: Interface of archive thesis

Figure 5 portrays the interface for the searching page where students and lecturers can search for completed FYP projects that have been uploaded by previous students. Figure 6 shows displays the interface for FYP projects' details after the users click the view button on the searching page. This page 
shows the FYP projects' details such as title, author, abstract, research area, date published, and supervisors' and coordinators' name. Therefore, it allows students and lecturers to know more about the details for a particular project.

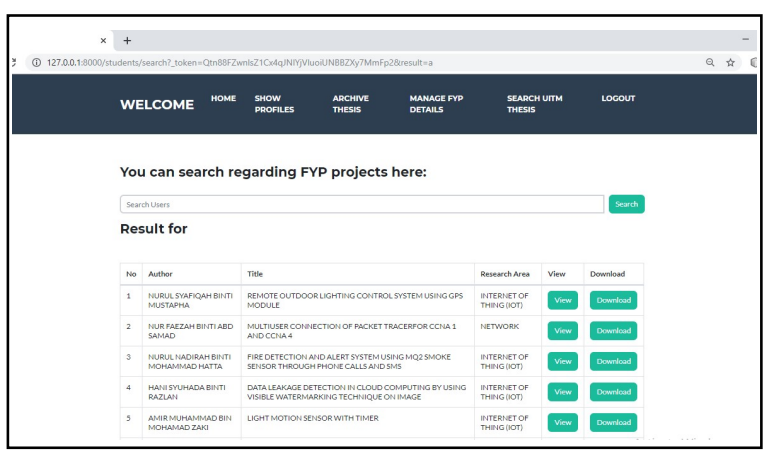

Figure 5: Interface for the searching page

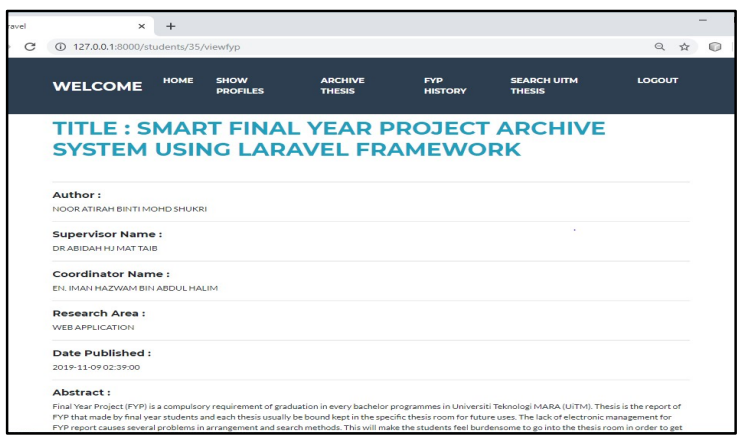

Figure 6: Interface for detail search of FYP project

SFYPAS also has a feature that helps the administrator add numerous students and lecturers by using an excel document. The administrator can upload the excel document filled with students' and lecturers' information then upload it through the system. Besides, the system also provides a register data page for a single student or lecturer where the administration can use it despite using the excel document upload that is suitable for registering massive data.

Moreover, the system also has an email notification where it will notify supervisors when their supervisees have requested to archive a new thesis where the supervisors need to approve or reject the application. Then, students will be notified about their archived thesis' status whether it has been approved or rejected. Moreover, to improve user experience, the system also can be accessed through smartphones.

In order to evaluate the effectiveness of this system, various testing has been done and the results and analysis are reported in the next section.

\section{RESULTS AND ANALYSIS}

This project uses a set of questionnaires that are met face-to-face and given online to the user to evaluate the system in terms of its heuristic evaluation, functionality, and user acceptance testing. The users were asked to use the system and their feedback are then recorded. There are ten questions asked in the user acceptance testing part to achieve the objectives of this project.

\section{Perceived Ease of Use (PEOU)}

Figure 7 displays the line graph that illustrates the perceived ease of use. Sixty percent of the respondents agreed that learning to operate the "Smart Final Year Project Archive System" is easy, while 33.3\% and $6.7 \%$ voted for strongly agree and average respectively. Then, $56.7 \%$ of the respondents agreed that it is easy to interact with the system while $33.3 \%$ and $10 \%$ voted for strongly agree and average respectively. Next, $53.3 \%$ of the respondents agreed that the system is clear and understandable, while $36.7 \%$ and $10 \%$ voted for strongly agree and average respectively. Besides, $46.7 \%$ of respondents agreed that it is easy to become skilful when using the system while $36.7 \%$ and $16.7 \%$ voted for strongly agree and average respectively. Lastly, $46.7 \%$ of the respondents agreed that the system is easy to use while $40 \%$ and $13.3 \%$ voted for strongly agree and average respectively. 


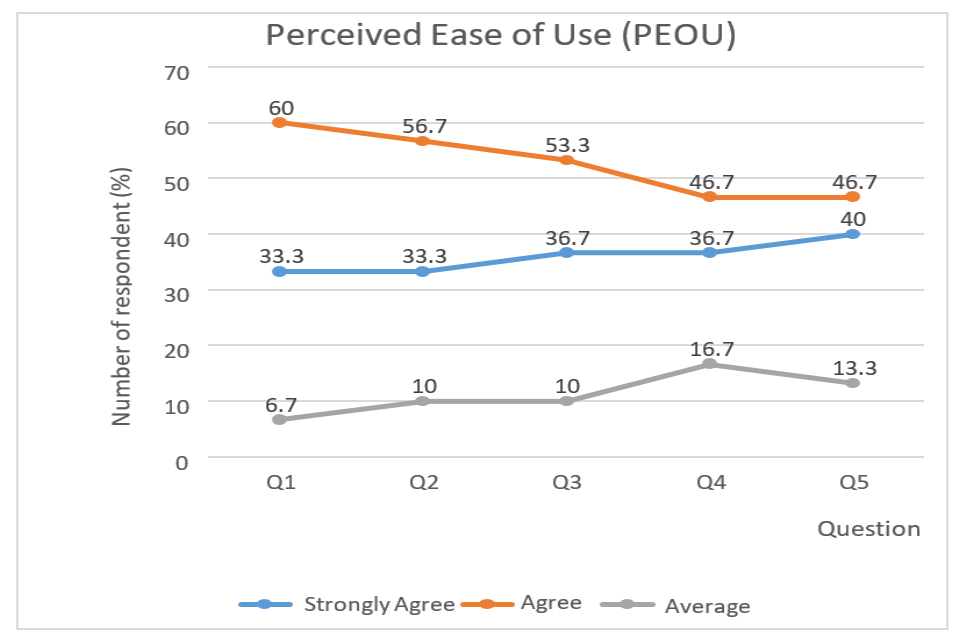

Figure 7: Result of Perceived Ease of Use

Hence, it can be inferred that the respondents agreed that the system is easy to be operated, easy to interact with, clear and understandable, easy to become skilful and easy to use.

\section{Perceived Usefulness (PU)}

Figure 8 represents the result of perceived usefulness.

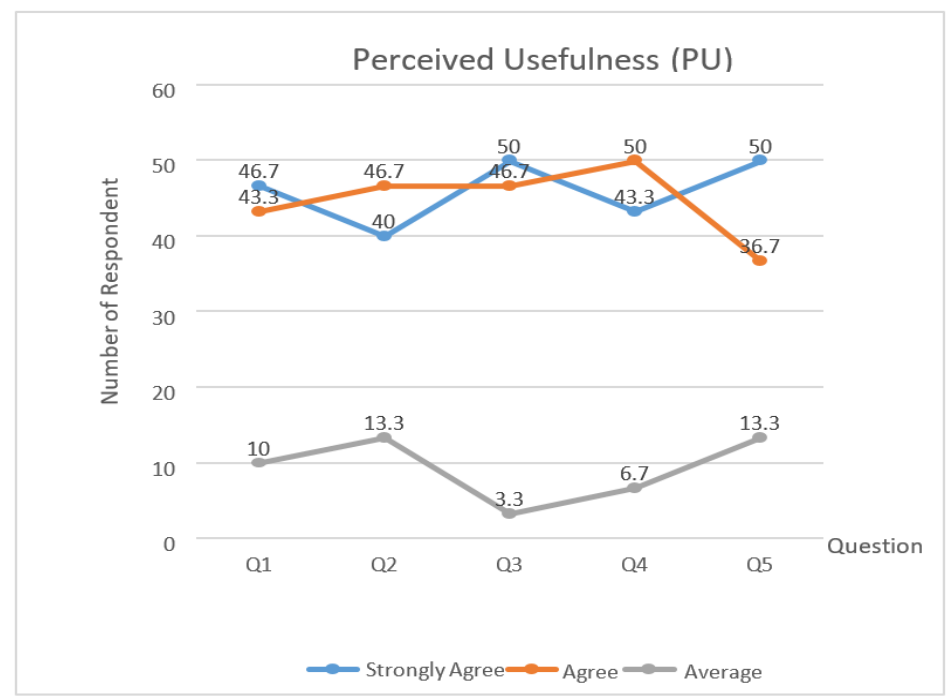

Figure 8: Result of Perceived Usefulness

As shown in the graph, $46.7 \%$ of the respondents strongly agreed that the Smart Final Year Project Archive System enables respondents to view all the details clearly and quickly while $43.3 \%$ and $10 \%$ voted for agree and average respectively. Then, $46.7 \%$ of the respondents agreed that the system enhances 
the effectiveness by receiving email notification while $40 \%$ and $13.3 \%$ voted for strongly agree and average respectively.

Besides, $50 \%$ of the respondents strongly agreed that the system also reduces the time spent on archiving and searching the thesis processes, while $46.7 \%$ and $3.3 \%$ voted agree and average respectively. Next, $50 \%$ of the respondents agreed that the system increases the respondents' productivity. Lastly, $50 \%$ of the respondents strongly agreed that the system's overall process is useful, while $36.7 \%$ and $13.3 \%$ chose agree and average respectively.

Therefore, this finding shows that the respondents agreed that the system is useful to use, can accomplish their task quickly, enhances the effectiveness of their life by receiving the email notification, reduce time spent and increase their productivity.

\section{Performance Testing (Load/Response Time)}

Load/Respond time testing has been conducted in order to determine whether the load time of the system is acceptable or not. For this test, the "Student List" page is chosen to be tested because this page retrieves most data from the database and the page is being tested on one device which is a laptop. The higher the response time, the lower the performance for the system. The result is being illustrated in the table form consists of the number of times reloading the page, average time, fastest time and slowest time. Table 3 reveals the load/response time testing result.

Table 3: Load/Response time on the Student List Page

\begin{tabular}{|l|l|l|l|}
\hline $\begin{array}{l}\text { Number } \\
\text { of Times }\end{array}$ & $\begin{array}{l}\text { Fastest } \\
\text { Time }(\mathbf{m s})\end{array}$ & $\begin{array}{l}\text { Slowest } \\
\text { Time }(\mathbf{s})\end{array}$ & $\begin{array}{l}\text { Average } \\
\text { Time } \\
\text { (ms) }\end{array}$ \\
\hline 10 & 368.54 & 2.04 & 473.301 \\
\hline 20 & 287.37 & 1.44 & 432.29 \\
\hline 30 & 309.85 & 1.61 & 359.419 \\
\hline
\end{tabular}

Based on the result, the load/response time of the system is acceptable. The result shows that the average response time is below $500 \mathrm{~ms}$ which is considered fast because getting a response time on a heavy load page under $500 \mathrm{~ms}$ is fast. However, the result might vary because of the devices that the user uses. Besides, the test was conducted only using one concurrent user. The higher number of concurrent users, the higher the response time users will get.

\section{Discussion of Results}

The results present positive outcome from all the functionality, heuristic evaluation, user acceptance with technology acceptance model (TAM) and performance testing. The findings from the evaluation and testing clearly indicate the information provided within the system is useful and the website is welldesigned. Thus, the archived projects can be viewed by the junior or upcoming students as references during the final year where the students can search the archived projects by entering the keywords related to the students' research area. Hence, this system can become an effective solution which can reduce the workload of lecturers where the lecturers can view the data about supervision, coordinator and examiner history so that they can update their current curricular vitae $(\mathrm{CV})$ or career advancement purposes.

Additionally, this system can help the administrator to add numerous numbers of students and lecturers in a better way by using MS Excel documents where administrators can upload the document that are filled 
with students' and lecturers' information onto the system. Despite using the excel document upload that is suitable to register massive data, the system also provides register data page for single student or lecturer. The system can also be accessed through smart phone so that it is user friendly. Besides, the system also provides email notification which notifies supervisors when their supervisees have requested to archive a new thesis. The supervisors can then approve or reject the request. Then, students will be notified about the status of their archived thesis whether it has been approved or rejected.

\section{CONCLUSION AND RECOMMENDATION}

This research was carried out to design and develop a web-based smart archive system that has the ability to archive a new thesis and search uploaded thesis based on keywords entered by the users. SFYPAS also can provide the supervision history where it shows the lists of students that have been supervised by a particular lecturer. It also displays the statistics of current and previous research areas. This information helps the FYP coordinator (system administrator) determine the distribution of students in specific research fields. This research has achieved the research objectives and it is proven that the system can satisfy users. Nevertheless, the system can be improved to be more efficient, effective and user-friendly by considering certain human-computer interaction values. SFYPAS has efficiently enables the administrator (FYP coordinator) to forecast the potential focus research fields and make any plan or preparation to ensure that all the research areas are strategically distributed. As a result, the administrator does not overlook for the specific research areas in the faculty.

\section{REFERENCES}

Abidin, SSZ. and Husin, M.H. (2018), Improving accessibility and security on document management system: A Malaysian case study, Applied Computing and Informatics, Vol. 16 No. 1/2, pp. 137154. https://doi.org/10.1016/j.aci.2018.04.002

Beta Social Compare (2019). PHP frameworks comparison, Available at : https://socialcompare.com/en/comparison/php-frameworks-comparison

Chen, X., Ji, Z., Fan, Y., \& Zhan, Y. (2017). Restful API Architecture Based on Laravel Framework, Journal of Physics: Conference Series, Volume 910, The 2017 International Conference on Cloud Technology and Communication Engineering (CTCE2017) 18-20 August 2017, Guilin, China.

Edzan, N. (2015). University Libraries as University Archives: The Malaysian Experience. In: International Conference on Library and Information Science, 23-25 August 2015, Osaka, Japan. Retrieved on May 5, 2019 from http://eprints.um.edu.my/14329/1/Edzan_2015_2325_August_Osaka_\%281\%29.pdf

Elmtiyaz. (n.d.). [University Sains Islam Malaysia Institutional Repository]. Retrieved April 10, 2019 from http://ddms.usim.edu.my/

Etheses. (n.d.). [UUM Electronic Theses and Dissertation]. Retrieved April 10, 2019 from http://etd.uum.edu.my/

Hustinawati, H., Kurnia Himawan, A., \& Latifah, L. (2014). Performance Analysis Framework Codeigniter and CakePHP in Website Creation. International Journal of Computer Applications, 94(20), 6-11. https://doi.org/10.5120/16549-5946 
Laaziri, M., Benmoussa, K., Khoulji, S., Larbi, K. M., \& Yamami, A. El. (2019). A comparative study of laravel and symfony PHP frameworks. International Journal of Electrical and Computer Engineering, 9(1), 704-712.https://doi.org/10.11591/ijece.v9i1.pp.704-712

Malik, S., Al-youbi, S. A., Al-youbi, S. B., Hussein, R., Dweik, G., \& Arif, S. (2018). Web-based Archive Management and Student Guidance for Final Year Projects. The Journal of Organizational Management Studies, 2018. https://doi.org/10.5171/2018

Pop, D. P., \& Altar, A. (2014). Designing an MVC model for rapid web application development. Procedia Engineering, 69, 1172-1179. https://doi.org/10.1016/j.proeng.2014.03.106

Securedatamgt. (2015). What is Archiving and Why is it important? Retrieved on 27 November 2019 from https://www.securedatamgt.com/blog/what-is-archiving/

Verma, A. (2014). MVC Architecture: a Comparitive Study Between Ruby on Rails and Laravel. Indian Journal of Computer Science and Engineering (IJCSE), 5(5), 196-198. 